\title{
Article
}

\section{The qual-CAT: applying a rapid review approach to qualitative research to support clinical decision-making in speech-language pathology practice}

Skeat, Jemma and Roddam, Hazel

Available at http://clok.uclan.ac.uk/26073/

Skeat, Jemma and Roddam, Hazel ORCID: 0000-0002-0637-1801 (2019) The qual-CAT: applying a rapid review approach to qualitative research to support clinical decision-making in speech-language pathology practice. EvidenceBased Communication Assessment and Intervention, 13 (1-2). pp. 3-14. ISSN $1748-9539$

It is advisable to refer to the publisher's version if you intend to cite from the work. http://dx.doi.org/10.1080/17489539.2019.1600292

For more information about UCLan's research in this area go to http://www.uclan.ac.uk/researchgroups/ and search for <name of research Group>.

For information about Research generally at UCLan please go to http://www.uclan.ac.uk/research/

All outputs in CLoK are protected by Intellectual Property Rights law, including Copyright law. Copyright, IPR and Moral Rights for the works on this site are retained by the individual authors and/or other copyright owners. Terms and conditions for use of this material are defined in the policies page. 


\section{Title:}

The qual-CAT: applying a rapid review approach to qualitative research to support clinical decision-making in speech-language pathology practice.

\section{Authors:}

Jemma Skeat ${ }^{\mathrm{a} *}$ and Hazel Roddam ${ }^{\mathrm{b}}$

${ }^{a}$ Department of Audiology and Speech Pathology, University of Melbourne, Australia;

${ }^{b}$ School of Health Sciences, University of Central Lancashire, United Kingdom

*For correspondence email jskeat@unimelb.edu.au

Source of funding and declaration of interest: None 


\title{
The qual-CAT: applying a rapid review approach to qualitative research to support clinical decision-making in speech-language pathology practice.
}

\begin{abstract}
Systematic reviews and meta-syntheses of qualitative research produce 'a sum greater than its parts'. Qualitative findings are examined alongside one another, and new insights are discovered about the topic under consideration. However, a barrier to clinicians undertaking these reviews is the time and knowledge required. Rapid review approaches, such as the Critically Appraised Topic (CAT), have recently been promoted in speech-language pathology, encouraging strategic, clinically driven examination of key research in focused topic areas, with the aim of supporting clinical decision-making. A strength of the CAT approach is that it supports interpretation and use of evidence by people who are not experts in the methodologies used. Additionally, CATs reduce the time input required by focusing on the best evidence available, and take a pragmatic approach to analysis across studies. While CAT methodologies have been detailed in relation to quantitative research, qualitative CAT methodologies have not specifically been discussed. Searching, ranking of research strength, appraisal and analysis methods are all likely to vary for qualitative CATs. This paper proposes and details a methodology for a "qual-CAT" approach, providing examples and steps that support the use of this methodology in practice.
\end{abstract}

Keywords: qualitative, critical appraisal, evidence-based practice 


\section{Introduction}

Qualitative research approaches have been on the radar of the profession of speech-language pathology since at least the late 1980s (Eastwood, 1988). By the early 2000s, Damico and Simmons-Mackie noted, “qualitative research is finding a niche in our discipline” (2003, p. 139). Qualitative research provides insights into issues that are important for decision-makers in policy and practice to be aware of (Daly et al., 2007). This includes supporting our understanding of consumer's perspectives on treatment processes and outcomes, opening our profession up to the perspectives of clients from different cultural, linguistic and social backgrounds, and even supporting our understanding of what communication is (Damico \& Simmons-Mackie, 2003).

When it comes to using qualitative research to inform practice, individual studies may provide useful insights. However, as with quantitative research, evidence that has been synthesised or summarised across more than one study provides a stronger basis for evidence-based practice (Haynes, 2001). Undertaking evidence synthesis requires reviewing the literature, guided by a focused question, appraising the quality of identified studies, conducting an analysis across studies, and forming a judgement about how the literature answers the question and the resulting recommendations for practice. There are several approaches to this task of evidence review and synthesis, including systematic reviews, systematised reviews, scoping reviews and rapid reviews, explored in detail by Grant and Booth (2009). The systematic review is perhaps the most well-known, and has been applied to qualitative research for many years (e.g., Booth et al., 2018; Noyes et al., 2018; Sandelowski \& Barroso, 2003; Thomas \& Harden, 2008). There is evidence of the applicability of qualitative systematic reviews within speech-language pathology (Baxter, Enderby, Evans, \& Judge, 2012; Brown, Worrall, Davidson, \& Howe, 2012; James, 2011). A 
key limitation of systematic review approaches- qualitative or quantitative- is the time and resources needed to undertake them (Jones, 2004; Munn, Lockwood, \& Moola, 2015). Further, expertise in qualitative research is suggested to be necessary for full qualitative meta-analysis (Jones, 2004) which may make these approaches less attractive to individuals or teams of clinical or academic staff without this specific expertise. Acknowledging these limitations, rapid review techniques have recently become more popular, including the Critically Appraised Topic, explored below. A comparison of the key features of systematic reviews versus rapid reviews is shown in table 1.

\section{INSERT TABLE 1 ABOUT HERE}

\section{The Critically Appraised Topic (CAT)}

A Critically Appraised Topic (CAT) is a type of rapid review. A CAT offers a pragmatic approach for examining the evidence base across a focused area, driven by a clinical question. The aim is to identify and rapidly appraise the ‘top’ literature (White, Raghavendra, \& McAllister, 2017). Like other forms of rapid review, the CAT approach restricts the searching component of the review, and simplifies the analysis of studies, while keeping the appraisal rigorous and the overall approach transparent (White et al., 2017). This is characterised by Grant and Booth (2009) as a 'quick but not dirty’ approach to evidencebased practice. Transparency in reporting of the steps taken, and acknowledgement of the implications of limitations is important, and supports the CAT to provide a meaningful and rigorous approach to evidence synthesis, despite the 'shortcuts' taken compared to a full systematic review (Grant and Booth, 2009).

The CAT approach to rapid review has been applied for many years in health and 
allied disciplines (Caldwell, Whitehead, Fleming, \& Moes, 2008; Fetters et al, 2004; Foster, Barlas, Chesterton, \& Wong, 2001; Hardin \& Robertson, 2006; Sadigh, Parker, Kelly, \& Cronin, 2012; Wyer, 1997). Authors have particularly emphasised the use of CATs by teams of clinicians, in order to inform a 'clinical conclusion' (Fetters et al., 2004). The CAT is a useful approach to answer questions that arise about individual clients in a way that is closer to the point of care (Sadigh et al, 2012). Additionally, CATs use less demanding analysis techniques to combine or synthesise findings than systematic reviews, making them more practical for both creating and using in practice (White et al, 2017). The use of CATs in speech-language pathology has been recently discussed and demonstrated (Watt \& White, 2018; White et al., 2017), and the approach has been applied successfully by speech pathologists in practice who use this as a practical, relevant approach to understanding the evidence for practice (Kelly, Miles Kingma, \& Robinson, 2010).

Applying the CAT approach to qualitative research may be one way to support clinicians to approach, synthesise and apply qualitative evidence to practice in a practical but rigorous way. To our knowledge, the specific methodological steps to be undertaken when a CAT question is qualitative, rather than quantitative, have not been detailed. We recently undertook a qualitative CAT based on the question "what do caregivers of preschool-aged children with speech, language or communication disorders (2-5 years of age) think of their involvement in speech-language pathology intervention in community-based settings?” (Skeat and Roddam, submitted). This experience supported our consideration of an appropriate 'qual-CAT' methodology. In this paper, we outline the major methodological steps involved to undertake a CAT appraisal of qualitative studies: developing a clinical question, searching the literature, evaluating the quality of each study, and synthesising the chosen studies to create a 'clinical bottom line'. While the steps described are guided by the original CAT method, they may be useful when considering any rapid appraisal of qualitative 
literature.

\section{Methodological steps}

\section{Developing a qualitative clinical question}

All evidence synthesis approaches begin with the development of a question, which ensures that the topic has been clarified, and drives the search strategy. Formulations similar to the popular PICO (Population, Intervention Comparison, Outcome) have been proposed for qualitative research. These include PICo (Population, Interest, Context) and SPIDER (Sample, Phenomenon of Interest, Design, Evaluation, Research type) (Cooke, Smith, \& Booth, 2012). Others have recommended simply adding the study type (qualitative or quantitative) to the end of the normal PICO to create PICOS (Methley, Campbell, ChewGraham, McNally, \& Cheraghi-Sohi, 2014). These approaches give various levels of information to the searcher, as Table 2 illustrates. We suggest that any of these approaches are appropriate to formulating a question for a CAT. The PICo approach, in our view, is the most useful for supporting the development of a literal question that includes the key search terms, which is the point (Cooke et al., 2012). However, clinicians may find the SPIDER approach useful if they are interested in a particular approach to qualitative research (e.g., observational research versus interviews), and want to specify this.

\section{INSERT TABLE 2 ABOUT HERE}

\section{Searching the literature}

Searching in a CAT is systematic, but scaled back. The searcher is not attempting to comprehensively identify all possible articles in an area, but to identify the key research in relation to the clinical question (White et al., 2017). In practice, this means focusing the 
search on key places that are likely to yield the best evidence. For quantitative CATs, starting with secondary (pre-appraised) literature, such as existing systematic reviews or syntheses is recommended (White et al., 2017). This rule applies to qualitative research as well, although databases of pre-appraised evidence or systematic reviews (such as SpeechBITE) do not exist for qualitative research. Hence the search needs to begin within primary research databases, which will allow identification of published systematic reviews of qualitative research and other primary qualitative research. There are relatively few published qualitative studies in any clinical area, hence a very focused strategy is needed to maximize the greatest possibility of 'hits'. Table 3 illustrates the very wide differences in qualitative research available through commonly used primary research databases such as Medline. These differences are important to be aware of in preparing a search that has the greatest chance of identifying key qualitative studies in an area.

Qualitative papers more frequently require abstract and even full paper reading before it is clear whether they answer the guiding question for a qualitative synthesis (Jones, 2004). Thus, in keeping with the aim for a rapid and focused search, specificity in searching is important, and a narrower search with focused terms is better, leaving less room for extraneous, and likely irrelevant, studies to be included in the search results (Harris et al, 2017). Searchers should be aware that many articles identified by title or abstract as 'qualitative' may turn out not to be so once the full paper is read, while others may have titles that describe the study findings, without identifying themselves specifically as 'qualitative' (Jones, 2004; Evans, 2002). Further complicating searches, a diverse set of keywords may be relevant to qualitative research (Campbell et al, 2011); for example, terms such as view, opinion, perception, or perspective may be relevant, as may method-based terms such as interview or focus group. To focus the search and aim for the most relevant results for a qualCAT, making effective use of the subject headings (MESH or equivalent) is essential. Where 
this is not an option, using a 'title, abstract, keyword' search or equivalent, rather than simple keyword searches is advised. Search terms should also be focused on the clinical question (PICo or other format) to increase the specificity of results; for example, by specifying the age group of interest or the specific group of people whose views you are interested in (e.g., parents/caregivers versus speech-language pathologists or other service providers).

An important part of literature searching in a CAT is identifying the inclusion and exclusion criteria, ensuring that there is transparency about why particular studies were considered as candidates for the review, while others were not (White et al, 2017). These criteria should be linked to the clinical question; for example, if the clinical question is about patient experiences of home-based health care, studies that focus on patient experiences of health care in other settings (e.g., hospitals) could be excluded. Most importantly, in the case of the qual-CAT, studies should be excluded if they do not present a depth of qualitative findings suitable for synthesis. A key indicator for this is that the study includes collection of rich, detailed data (e.g., interviews, observations, focus groups), versus narrow, limited data (e.g., open-ended survey questions or 'comments'). Sandelowski and Barroso (2003) also argued that there is a minimum level of qualitative analysis required in order to include a study as part of synthesis approach. At a minimum, there should be evidence that the qualitative researcher has discovered and attempt to understand the patterns within their data. Research which provides only case descriptions, participant quotes without analysis, stories or histories with minimal or no identification of patterns in the data, should be discounted. Similarly, papers where there is an emphasis on lists or inventories (with or without percentages or frequencies reported) of topics raised by participants, without consideration of what these patterns describe or define, would not be suitable for a qual-CAT. The surface level of this type of analysis does not provide insights that could be used as a basis for qualitative synthesis, thus these papers should be excluded (Sandelowski and Barroso, 2003). 
INSERT TABLE 3 ABOUT HERE

\section{Identifying the 'top' qualitative research papers}

The CAT process deliberately limits the number of papers appraised; focusing, as stated above, on the 'top’ evidence in order to support best practice. Thus, once candidate papers have been determined using the searching and screening processes described above, the focus changes to identifying the top 3-5 papers for inclusion in the CAT (White et al, 2017). A quantitative CAT process typically uses a hierarchy of evidence to achieve this, ranking papers based on their research design (White et al, 2017). For example, Randomised Controlled Trials outrank observational studies. Higher ranked papers are presumed to provide more robust evidence for practice, and thus are included in the CAT.

In qualitative research, multiple factors, such as the methods used for sampling, data collection, data analysis and how conclusions are drawn from the data, may all impact on the strength of evidence (Daly et al, 2007). Thus, for a qual-CAT, a qualitative-specific hierarchy should be used, such as that proposed by Daly et al (2007). There are four levels to this hierarchy, with Level IV (the lowest) encompassing "limited but insight provoking singlecase studies" (p. 44) while Level I studies are considered 'generalisable' and have the strongest evidence for practice. While Daly et al (2007) propose that these four levels represent “four distinct qualitative research designs” (p. 48), we suggest that research may not neatly fit into a single level of this hierarchy, but that the hierarchy is nevertheless a good support for understanding the strength of evidence a qualitative study provides. Table 4 provides an interpretation of Daly's hierarchy, with suggested questions that clinicians can use when reading qualitative research studies to determine where they sit in terms of the levels. 


\section{INSERT TABLE 4 ABOUT HERE}

While the hierarchy of qualitative evidence (Daly et al, 2007) provides a useful comparison of the likely strength of evidence each paper may provide, in making decisions about which papers to include in a qual-CAT, it is also worth considering whether the papers included are diverse enough to give a broad insight into the area being examined. The Cochrane Collaboration (Noyes et al., 2018) suggests that qualitative syntheses should include papers with lower methodological quality if the paper would provide additional insights into an area. This might include addressing areas of context, perspectives, or alternative lines of argument that would not otherwise be found in the 'top papers' in that area.

\section{Appraising the quality of each study}

Once the papers have been chosen and their strength of evidence is known, each selected paper is appraised to ensure that the ethical, methodological and reporting requirements for qualitative research have been met. As for quantitative research, checklists and templates are available to guide the reader to note specific points which may be strengths or weaknesses of particular studies. Qualitative appraisal tools are provided by bodies such as the Critical Appraisal Skills Program (http://www.casp-uk.net/casp-tools-checklists) or the Joanna Briggs Institute (http://joannabriggs.org/research/critical-appraisal-tools.html). As part of a CAT, the use of these tools supports critical reflection on whether or not a study, regardless of where it sits in the evidence hierarchy explored above, has flaws which potentially limit the usefulness of the findings, or which should be taken into account when considering the weight of the findings overall for supporting practice. It is recommended that team members undertake 
independent appraisal of the papers before comparing their rating and narrative comments to reach agreement on their final judgements. The transparency of this stage of the CAT process further strengthens the credibility and value of the resultant practice recommendations based on the CAT findings.

\section{Synthesising the findings}

An important part of a CAT is making sense of the findings across studies. For quantitative CATs, some level of meta-analysis may be applied; for example, in comparing relevant reported aspects (eg effect size) of standard versus comparison therapies (Sadigh et al, 2012). However, CATs keep the analysis scaled back compared to full systematic reviews; the aim is to understand what the studies combined are telling us, but this may be provided in a written summary, versus extensive statistical analyses (see Watt and White, 2018 for an example of this). With a qual-CAT, the analysis is a synthesis of the concepts generated across the studies reviewed. The overall aim is for "novel interpretations of findings" (Thorne, Jensen, Kearney, Noblit, \& Sandelowski, 2004, p. 1358), ie, a fresh perspective, not just a restating of the key themes in each study. The approach is not aggregative in the way that a quantitative meta-analysis is aggregative, i.e., adding together the findings of several studies in order to increase the sample size and hence the power and credibility of the results. Instead, qualitative synthesis is interpretive, and places emphasis on understanding the picture that the findings provide once examined together (Dixon-Woods et al, 2006).

There are several methods of qualitative synthesis detailed in the literature, including thematic synthesis, meta-ethnography, and meta-aggregation (Booth et al., 2018). While these approaches differ, their essential elements are 1) understanding and summarising the findings of each study, and 2) interpreting the findings across studies and considering what new insights they provide when examined side by side (Dixon-Woods et al., 2006). To our 
knowledge, there has been no discussion in the literature about approaches suitable for 'rapid qualitative synthesis'.

In practical terms, we suggest that synthesising the findings of a qual-CAT should include developing an overall precis of what each study contributes to our knowledge about the topic. This requires identifying the key findings of each study (concepts, themes, categories, etc) in relation to the qual-CAT PICo (or similar) question, and considering what the author has interpreted from these findings. The above should be concisely summarised, alongside the strength of evidence that each study provides. The author should then look for patterns across studies, and for similarities and differences in what has been expressed in each. A summary of these patterns may be expressed by theme(s) or concept(s): words or phrases that represent the underlying ideas identified across the studies. These may be new ideas, or fresh interpretations, deeper insights, or a richer understanding of existing ideas in these studies, drawn from the examination of the findings across studies as a whole. These patterns should be discussed with examples from the papers themselves.

Finally, using the qual-CAT question as a framework, the overarching message of the findings should be provided. This is the 'clinical bottom line', and as with traditional CATs this should be a clear, succinct summary of the take-home message for practice (White et al, 2017). It should tell the reader of the qual-CAT what these studies, when taken as a whole, tell us about the area of interest.

An example of these steps is provided in Skeat and Roddam (submitted) where we examined the qualitative evidence around parent involvement in speech-language pathology intervention for young children with communication needs.

\section{Conclusion}


The application of the CAT approach to qualitative research detailed here is designed to support people who are not experts in qualitative research to participate in rapid appraisal and synthesis of qualitative studies. Rapid appraisal approaches such as the CAT have the benefit of providing a structured but practical way of translating evidence to practice. While systematic, large scale reviews are necessary to definitively answer questions about practice, smaller scale but methodologically sound and transparent approaches are needed for clinical teams who need to know the bottom line of the evidence as quickly as possible. Thus, rapid appraisal approaches such as the qual-CAT have the clear potential to inform care planning at the individual patient and service management level. 


\section{References}

Baxter, S., Enderby, P., Evans, P., \& Judge, S. (2012). Barriers and facilitators to the use of high-technology augmentative and alternative communication devices: A systematic review and qualitative synthesis. International Journal of Language \& Communication disorders, 47(2), 115-129.

Booth, A., Noyes, J., Flemming, K., Gerhardus, A., Wahlster, P., van der Wilt, G. J., . . . Tummers, M. (2018). Structured methodology review identified seven (RETREAT) criteria for selecting qualitative evidence synthesis approaches. Journal of Clinical Epidemiology, 99, 41-52.

Brown, K., Worrall, L. E., Davidson, B., \& Howe, T. (2012). Living successfully with aphasia: A qualitative meta-analysis of the perspectives of individuals with aphasia, family members, and speech-language pathologists. International Journal of SpeechLanguage Pathology, 14(2), 141-155.

Caldwell, E., Whitehead, M., Fleming, J., \& Moes, L. (2008). Evidence-based practice in everyday clinical practice: Strategies for change in a tertiary occupational therapy department. Australian Occupational Therapy Journal, 55(2), 79-84.

Cooke, A., Smith, D., \& Booth, A. (2012). Beyond PICO: the SPIDER tool for qualitative evidence synthesis. Qualitative Health Research, 22(10), 1435-1443.

Daly, J., Willis, K., Small, R., Green, J., Welch, N., Kealy, M., \& Hughes, E. (2007). A hierarchy of evidence for assessing qualitative health research. Journal of Clinical Epidemiology, 60(1), 43-49.

Damico, J. S., \& Simmons-Mackie, N. N. (2003). Qualitative research and speech-language pathology: A tutorial for the clinical realm. American Journal of Speech-Language Pathology, 12(2), 131-143.

Dixon-Woods, M., Bonas, S., Booth, A., Jones, D. R., Miller, T., Sutton, A. J., . . Y Young, B. (2006). How can systematic reviews incorporate qualitative research? A critical perspective. Qualitative Research, 6(1), 27-44.

Eastwood, J. (1988). Qualitative research: An additional research methodology for speech pathology? British Journal of Disorders of Communication, 23(2), 171-184.

Evans, D. (2002). Database searches for qualitative research. Journal of the Medical Library Association, 90(3), 290.

Fetters, L., Figueiredo, E.M., Keane-Miller, D., McSweeney, D. J. \& Tsao, C. C. (2004). Critically appraised topics. Pediatric Physical Therapy, 16(1), 19-21

Foster, N., Barlas, P., Chesterton, L., \& Wong, J. (2001). Critically Appraised Topics (CATs): One method of facilitating evidence-based practice in physiotherapy. Physiotherapy, 87(4), 179-190. 
Grant, M. J., \& Booth, A. (2009). A typology of reviews: an analysis of 14 review types and associated methodologies. Health Information \& Libraries Journal, 26(2), 91-108.

Hardin, L. E., \& Robertson, S. (2006). Learning evidence-based veterinary medicine through development of a critically appraised topic. Journal of Veterinary Medical Education, 33(3), 474-478.

Harris, J. L., Booth, A., Cargo, M., Hannes, K., Harden, A., Flemming, K., ... \& Noyes, J. (2018). Cochrane Qualitative and Implementation Methods Group guidance seriespaper 2: methods for question formulation, searching, and protocol development for qualitative evidence synthesis. Journal of Clinical Epidemiology, 97, 39-48.

Haynes, R. B. (2001). Of studies, syntheses, synopses, and systems: the "4S" evolution of services for finding current best evidence. ACP Journal Club, 134, A11-14.

James, D. M. (2011). The applicability of normalisation process theory to speech and language therapy: a review of qualitative research on a speech and language intervention. Implementation Science, 6(1), 95.

Jones, M. L. (2004). Application of systematic review methods to qualitative research: practical issues. Journal of Advanced Nursing, 48(3), 271-278.

Kelly, T., Miles Kingma, R., \& Robinson, R. (2010). Building and supporting a multi-stream clinical evidence-based practice Network. In H. Roddam \& J. Skeat (Eds.), Embedding Evidence-Based Practice in Speech and Language Therapy: International Examples (pp. 129-138). UK: Wiley.

Khangura, S., Konnyu, K., Cushman, R., Grimshaw, J., \& Moher, D. (2012). Evidence summaries: the evolution of a rapid review approach. Systematic Reviews, 1(1), 10.

Methley, A. M., Campbell, S., Chew-Graham, C., McNally, R., \& Cheraghi-Sohi, S. (2014). PICO, PICOS and SPIDER: a comparison study of specificity and sensitivity in three search tools for qualitative systematic reviews. BMC Health Services Research, 14(1), 579.

Munn, Z., Lockwood, C., \& Moola, S. (2015). The development and use of evidence summaries for point of care information systems: a streamlined rapid review approach. Worldviews on Evidence-Based Nursing, 12(3), 131-138.

Noyes, J., Booth, A., Flemming, K., Garside, R., Harden, A., Lewin, S., . . Thomas, J. (2018). Cochrane Qualitative and Implementation Methods Group guidance paper 3: methods for assessing methodological limitations, data extraction and synthesis, and confidence in synthesized findings. Journal of Clinical Epidemiology, 97, 49-58.

Sadigh, G., Parker, R., Kelly, A. M., \& Cronin, P. (2012). How to write a critically appraised topic (CAT). Academic Radiology, 19(7), 872-888.

Sandelowski, M., \& Barroso, J. (2003). Classifying the findings in qualitative studies. Qualitative Health Research, 13(7), 905-923. 
Skeat, J., \& Roddam, H. (submitted). What do parents think about their involvement in speech-language pathology intervention? A Qualitative Critically Appraised Topic. Submitted to Evidence-Based Communication Assessment and Intervention.

Thomas, J., \& Harden, A. (2008). Methods for the thematic synthesis of qualitative research in systematic reviews. BMC Medical Research Methodology, 8(1), 45.

Thorne, S., Jensen, L., Kearney, M. H., Noblit, G., \& Sandelowski, M. (2004). Qualitative metasynthesis: reflections on methodological orientation and ideological agenda. Qualitative Health Research, 14(10), 1342-1365.

Watt, A., \& White, S. (2018). Efficacy of group versus individual therapy for advancing receptive and expressive language development for children aged 6-12 years within community settings: A critically appraised topic. Evidence-Based Communication Assessment and Intervention, 1-18.

White, S., Raghavendra, P., \& McAllister, S. (2017). Letting the CAT out of the bag: Contribution of critically appraised topics to evidence-based practice. Evidence-Based Communication Assessment and Intervention, 11(1-2), 27-37.

Wyer, P. C. (1997). The critically appraised topic: closing the evidence-transfer gap. Annals of Emergency Medicine, 30(5), 639-640. 
Table 1: Common review types, summarised from Grant and Booth (2009) and Khangura et al. (2012)

\begin{tabular}{|c|c|c|c|c|c|c|}
\hline & Aim & $\begin{array}{l}\text { Methodological } \\
\text { approach }\end{array}$ & Timeframe & Search & Appraisal & Analysis across studies \\
\hline $\begin{array}{l}\text { Systematic } \\
\text { review }\end{array}$ & $\begin{array}{l}\text { To collate the } \\
\text { evidence to answer } \\
\text { a specific research } \\
\text { question. The } \\
\text { findings may } \\
\text { identify a lack of } \\
\text { certainty in a } \\
\text { focused area, or } \\
\text { support } \\
\text { recommendations } \\
\text { for practice. }\end{array}$ & $\begin{array}{l}\text { Comprehensive, } \\
\text { systematic, } \\
\text { replicable, } \\
\text { transparent. } \\
\text { May be guided } \\
\text { by specific } \\
\text { guidelines (e.g., } \\
\text { Cochrane } \\
\text { Collaboration) }\end{array}$ & $\begin{array}{l}6 \text { months to } \\
2 \text { years }\end{array}$ & $\begin{array}{l}\text { Comprehensive; } \\
\text { however, may } \\
\text { be limited by } \\
\text { study type (e.g., } \\
\text { only } \\
\text { randomised } \\
\text { controlled } \\
\text { trials). }\end{array}$ & $\begin{array}{l}\text { Quality } \\
\text { assessment of } \\
\text { each study is } \\
\text { undertaken } \\
\text { using appraisal } \\
\text { tools. }\end{array}$ & $\begin{array}{l}\text { Typically aims for a meta-analysis } \\
\text { or meta-synthesis of studies to } \\
\text { bring together the information } \\
\text { contained in each and explore the } \\
\text { strength and consistency of } \\
\text { evidence. }\end{array}$ \\
\hline $\begin{array}{l}\text { Rapid } \\
\text { review }\end{array}$ & $\begin{array}{l}\text { To collate the 'best' } \\
\text { evidence available } \\
\text { to answer a very } \\
\text { specific question, } \\
\text { usually guided by } \\
\text { an immediate } \\
\text { practice or policy } \\
\text { need. The findings } \\
\text { should be useful to } \\
\text { guide decision- } \\
\text { making. }\end{array}$ & $\begin{array}{l}\text { Systematic, } \\
\text { replicable and } \\
\text { transparent; } \\
\text { several possible } \\
\text { approaches } \\
\text { including } \\
\text { Critically } \\
\text { Appraised } \\
\text { Topics (CAT) }\end{array}$ & $<5$ weeks & $\begin{array}{l}\text { Systematic but } \\
\text { may be } \\
\text { deliberately } \\
\text { limited, aiming } \\
\text { to find the 'top' } \\
\text { studies in a } \\
\text { particular area. }\end{array}$ & $\begin{array}{l}\text { Quality } \\
\text { assessment of } \\
\text { each study is } \\
\text { undertaken } \\
\text { using appraisal } \\
\text { tools. }\end{array}$ & $\begin{array}{l}\text { Typically aims for a summary of } \\
\text { the evidence across studies with a } \\
\text { limited form of meta-analysis or } \\
\text { meta-synthesis to understand the } \\
\text { 'bottom line' of findings. }\end{array}$ \\
\hline
\end{tabular}


Table 2: Example of PICo, SPIDER and PICOS approaches to propose a qualitative clinical question

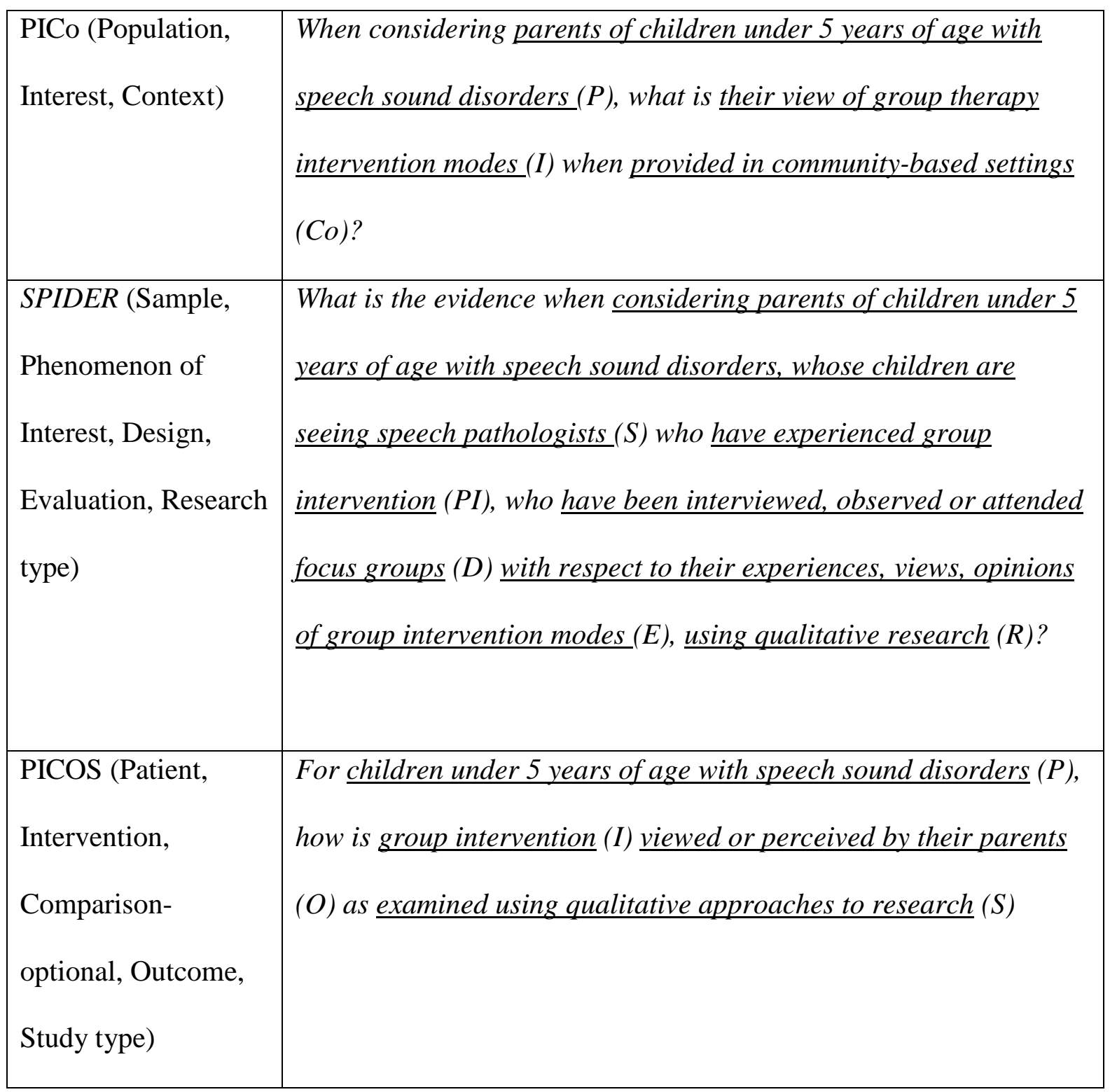


Table 3: Use of common databases for finding qualitative research relevant to speechlanguage pathology

\begin{tabular}{|c|c|c|}
\hline Database & Search terms & $\begin{array}{l}\text { Titles } \\
\text { identified }\end{array}$ \\
\hline Medline (Ovid) & $\begin{array}{l}\text { MESH: Speech Therapy OR Speech-Language } \\
\text { Pathology; OR ("speech patholog*" or "speech } \\
\text { therap*" or "speech-language patholog*" or } \\
\text { "speech and language patholog*" or "speech and } \\
\text { language therap*").mp. } \\
\text { AND MESH: grounded theory/ or qualitative } \\
\text { research/ }\end{array}$ & 94 \\
\hline CINAHL & $\begin{array}{l}\text { Subject Headings: ("Speech Therapy+") OR } \\
\text { ("Research, Speech-Language-Hearing Therapy") } \\
\text { OR } \\
\text { Text word: ("speech patholog*" or "speech } \\
\text { therap*" or "speech-language patholog*" or } \\
\text { "speech and language patholog*" or "speech and } \\
\text { language therap*") } \\
\text { AND } \\
\text { Subject Heading:"Qualitative Studies+") }\end{array}$ & 1663 \\
\hline EMBASE & $\begin{array}{l}\text { MESH: Speech therapy OR } \\
\text { ("speech patholog*" or "speech therap*" or } \\
\text { "speech-language patholog*" or "speech and } \\
\text { language patholog*" or "speech and language } \\
\text { therap*").mp. } \\
\text { AND } \\
\text { MH “Qualitative research" }\end{array}$ & 163 \\
\hline $\begin{array}{l}\text { Linguistics and } \\
\text { Language } \\
\text { Behavior } \\
\text { Abstracts (LLBA) }\end{array}$ & $\begin{array}{l}\text { ("speech patholog*" or "speech therap*" or } \\
\text { "speech-language patholog*" or "speech and } \\
\text { language patholog*" or "speech and language } \\
\text { therap*") in document text, } \\
\text { AND ("qualitative research") in document text }\end{array}$ & 268 \\
\hline Psychinfo & $\begin{array}{l}\text { ("speech patholog*" or "speech therap*" or } \\
\text { "speech-language patholog*" or "speech and } \\
\text { language patholog*" or "speech and language } \\
\text { therap*").mp. } \\
\text { AND } \\
\text { MH Qualitative research }\end{array}$ & 27 \\
\hline
\end{tabular}




\begin{tabular}{|l|l|l|}
\hline ERIC & $\begin{array}{l}\text { Text word: ("speech patholog*" or "speech } \\
\text { therap*" or "speech-language patholog*" or } \\
\text { "speech and language patholog*" or "speech and } \\
\text { language therap*") } \\
\text { AND }\end{array}$ & 101 \\
Text word: "Qualitative research" & $\begin{array}{l}\text { Title, Abstract or Keyword: "speech patholog*" } \\
\text { OR "speech therap*" OR "speech-language } \\
\text { patholog*" OR "speech and language patholog*" } \\
\text { OR "speech and language therap*" }\end{array}$ & 689 \\
& $\begin{array}{l}\text { AND Title, Abstract or Keyword: "qualitative } \\
\text { research" ) }\end{array}$ & \\
\hline
\end{tabular}


Table 4: Questions and indicators to support analysis of qualitative research reports, based on the hierarchy by Daly et al (2007)

\begin{tabular}{|c|c|c|c|c|}
\hline Questions to ask & Level I & Level II & Level III & Level IV \\
\hline $\begin{array}{l}\text { Who are the } \\
\text { participants? }\end{array}$ & $\begin{array}{l}\text { A diverse range of } \\
\text { people or situations, } \\
\text { relevant to the research } \\
\text { aims }\end{array}$ & $\begin{array}{l}\text { A single or restricted group } \\
\text { of people or situations } \\
\text { relevant to the research aims }\end{array}$ & $\begin{array}{l}\text { A single group of } \\
\text { people or situations } \\
\text { relevant to the } \\
\text { research aims }\end{array}$ & $\begin{array}{l}\text { Single case or series of cases } \\
\text { relevant to the research aims. }\end{array}$ \\
\hline $\begin{array}{l}\text { How were participants } \\
\text { chosen? }\end{array}$ & $\begin{array}{l}\text { Deliberately chosen, } \\
\text { based on literature and } \\
\text { theory and the analysis } \\
\text { itself. Sampling of } \\
\text { participants happens } \\
\text { throughout the study, } \\
\text { and participants are } \\
\text { chosen deliberately to } \\
\text { extend on the findings } \\
\text { already discovered. This } \\
\text { leads to a diverse } \\
\text { sample. } \\
\text { Sampling may be } \\
\text { described as theoretical, } \\
\text { grounded, iterative, } \\
\text { cyclical, or driven by the } \\
\text { analysis. }\end{array}$ & $\begin{array}{l}\text { Deliberately chosen, based on } \\
\text { the literature and theory. } \\
\text { Sampling may be described } \\
\text { as purposive. It may be } \\
\text { limited to one group that is } \\
\text { explored in depth, or several } \\
\text { subgroups. } \\
\text { There is evidence that the } \\
\text { researchers have deliberately } \\
\text { attempted to include diverse } \\
\text { views. }\end{array}$ & $\begin{array}{l}\text { Deliberately chosen } \\
\text { but based on a } \\
\text { limited area of study, } \\
\text { a group already } \\
\text { participating in } \\
\text { something else, or } \\
\text { people available in a } \\
\text { centre or place. } \\
\text { Sampling is not } \\
\text { deliberately planned } \\
\text { to include diverse } \\
\text { views. }\end{array}$ & $\begin{array}{l}\text { Deliberately chosen based on } \\
\text { literature and theory, but } \\
\text { limited in number and with the } \\
\text { purpose of in-depth case } \\
\text { description/analysis. }\end{array}$ \\
\hline $\begin{array}{l}\text { When did sampling } \\
\text { stop? }\end{array}$ & $\begin{array}{l}\text { Data saturation is } \\
\text { reached where further } \\
\text { sampling (e.g., } \\
\text { additional interviews) } \\
\text { does not bring further }\end{array}$ & $\begin{array}{l}\text { A planned number of } \\
\text { participants or situations are } \\
\text { included, or are restricted by } \\
\text { initial sampling (ie, further } \\
\text { sampling is not undertaken to }\end{array}$ & $\begin{array}{l}\text { A planned number of } \\
\text { participants or } \\
\text { situations are } \\
\text { included. }\end{array}$ & $\begin{array}{l}\text { A planned and restricted } \\
\text { number of participants or } \\
\text { situations are included. }\end{array}$ \\
\hline
\end{tabular}




\begin{tabular}{|c|c|c|c|c|}
\hline & $\begin{array}{l}\text { new ideas to the } \\
\text { analysis. This should be } \\
\text { stated in the paper. }\end{array}$ & $\begin{array}{l}\text { extend knowledge of } \\
\text { concepts or emerging } \\
\text { themes). }\end{array}$ & & \\
\hline $\begin{array}{l}\text { What do the findings } \\
\text { look like? }\end{array}$ & $\begin{array}{l}\text { A theoretical or } \\
\text { conceptual model, or a } \\
\text { well-defined set of } \\
\text { concepts that define, } \\
\text { explore or explain the } \\
\text { underlying issues, } \\
\text { processes, and the } \\
\text { relationships between } \\
\text { them. }\end{array}$ & $\begin{array}{l}\text { A well-defined set of } \\
\text { concepts or themes that } \\
\text { explore and attempt to } \\
\text { understand the underlying } \\
\text { issues for the participants. } \\
\text { A major difference between } \\
\text { findings at level I and level II } \\
\text { is that the relationship } \\
\text { between concepts is not } \\
\text { explored in level II. }\end{array}$ & $\begin{array}{l}\text { A set of descriptive } \\
\text { categories that } \\
\text { summarise people's } \\
\text { views, opinions, } \\
\text { experiences, or } \\
\text { observations made. }\end{array}$ & $\begin{array}{l}\text { An in-depth analysis of each } \\
\text { participant, perhaps focusing } \\
\text { on their experience, views or } \\
\text { 'story', with insights gained } \\
\text { from participants highlighted. } \\
\text { May be presented as } \\
\text { descriptive categories. }\end{array}$ \\
\hline $\begin{array}{l}\text { How is the evidence for } \\
\text { practice discussed? }\end{array}$ & $\begin{array}{l}\text { The discussion situates } \\
\text { the findings within the } \\
\text { literature and addresses } \\
\text { generalisability, } \\
\text { outlining the } \\
\text { implications for practice } \\
\text { and/or policy. }\end{array}$ & $\begin{array}{l}\text { Areas of weakness are } \\
\text { identified and implications } \\
\text { for practice and policy may } \\
\text { be indicated in this context. }\end{array}$ & $\begin{array}{l}\text { Considerations for } \\
\text { practice may be } \\
\text { identified, based on } \\
\text { the defined group. }\end{array}$ & $\begin{array}{l}\text { The discussion highlights a } \\
\text { new phenomena or idea that } \\
\text { has been identified through } \\
\text { this study which might be } \\
\text { useful for practitioners to } \\
\text { know. }\end{array}$ \\
\hline
\end{tabular}


